\title{
Empirical Study on Proactive Personality and Entrepreneurial Intention of Full Time Mother \\ QI Xiaolin ${ }^{1, \mathrm{a}}$ and LUO Ye $\mathrm{e}^{2, \mathrm{~b}}$ \\ ${ }^{1}$ Wuhan Technology and Business University, Wuhan 430000, China; \\ ${ }^{2}$ Shanghai Future High-tech Co., Ltd., Shanghai 200000, China; \\ a10120217@qq.com, b838026238@qq.com
}

Keywords: Proactive personality, Entrepreneurial intention, Entrepreneurial attitude

\begin{abstract}
In the era of the Internet and e-commerce, some full-time Mothers open online business has achieved some success. It makes more full-time Mothers to initiate the idea of entrepreneurship. To help full-time mother to make rational decisions, in this paper, through literature retrieval and questionnaire survey, investigate 100 full-time mother proactive personality, entrepreneurial attitude and entrepreneurial intention. By SPSS data analysis, it get the active personality entrepreneurial attitude have positive correlation on the entrepreneurial intention. Research clearly provides the reference of business or individual career development for a full-time mother.
\end{abstract}

\section{Introduction}

A full time mother is a woman who stays at home without a job and focuses on taking care of children's everyday life as a mother. Thanks to reform and opening up and economic development, the occupational status of women in China has been improved. Meanwhile the one child policy has gradually turned "full time mother" into a new type of job. Now, the number of women being a "full time mother" voluntarily is increasing. However, a lot of family problems are caused gradually since women choose to be a full time mother due to lack of economic source, single center of life and lack of connections with outside world. Meanwhile, the development of internet and e-commerce helps some full time mothers succeed in starting a business by opening online stores. The report on "what you earn is not money, but happiness" arouses the desire of more full time mothers start a business. Is every full time mother suitable for starting a business? This paper studies the relationship of proactive personality with entrepreneurial intention, and performs a questionnaire survey based on the proactive personality scale, so as to provide the theoretical basis for full time mothers to start a business and the reference for their entrepreneurial decisions.

\section{Research Hypotheses}

With regard to proactive personality and entrepreneurship, some studies prove that proactive personality has positive correlation with entrepreneurial intention, entrepreneurial process and behaviors, and entrepreneurial results. Through the study on college students and MBA students, Crant (1996) found the significant positive correlation between proactive personality and entrepreneurial intention. After controlling some variables, e.g. gender, educational background and whether a parent was an entrepreneur, proactive personality could provide more supports for the prediction of entrepreneurial intention. In the study on general managers of small enterprises, Becherer and Maurer (1999) noticed the positive influence of proactive personality on entrepreneurship. Based on the studies of predecessors, Luthje \& Frank claimed that the influencing factors of entrepreneurial intention mainly include personality traits and environmental factors, and risk-taking tendency leads to more active entrepreneurial attitude and affects entrepreneurial intention. Personality traits can affect entrepreneurial intention through the mediator-attitude.

Above all, there are some connections among entrepreneurial attitude, proactive personality and entrepreneurial intention. The general idea of this study is to empirically analyze and explore the 
influence of proactive personality on entrepreneurial intention of full time mother, and the relevant hypotheses are brought forth to build the following model:

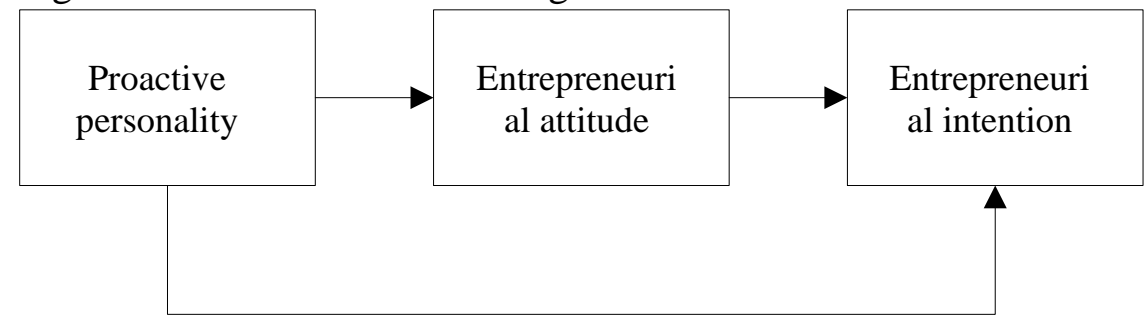

Fig. 1 General frame diagram of the research

Through the above model, we can bring forward the following hypotheses:

Hypothesis 1: The stronger proactive personality, the stronger entrepreneurial intention;

Hypothesis 2: The stronger entrepreneurial attitude, the stronger entrepreneurial intention;

Hypothesis 3: Entrepreneurial attitude is a mediator variable between proactive personality and entrepreneurial intention.

\section{Research Design}

Design of Variables and Questionnaire. (1) Explained variables. The entrepreneurial intention is provided with 4 questions and 6 point scale to give 1 to 6 points in the comments from "Totally Wrong” to “Totally Right”.

(2) Explanatory variables. This paper consults with the overseas proactive personality scales, and borrows the proactive personality scale developed by Bateman (1993) and other scholars with 17 entries and its simplified scale (including 10 entries, 6 entries, 5 entries or 4 entries). Then, these 17 entries are converted into more understandable entries. The questions are designed with 6 point scale to give 1 to 6 points in the comments from "Totally Wrong” to "Totally Right".

(3) Mediator variables. Entrepreneurial attitude is measured with 7 questions and 6 point scale to give 1 to 6 points in the comments from “Totally Wrong” to "Totally Right”.

Sample and Features. This study takes the full time mothers from several residential communities in Wuhan City, Hubei Province, namely, Jinse Yayuan community, Fuxinghuiyu Fuxing City community and Huaanli Sub-district. Among 120 copies of questionnaire distributed, 116 copies were returned with 37 from Jinse Yayuan, 46 from Fuxing City and 37 from Huaanli.

Among them, 100 valid copies were selected based on the nature of respondent. As this questionnaire was designed for full time mothers, 11 copies from the respondents who were not full time mothers were removed. Moreover, 9 copies were obviously unacceptable (as they were carelessly completed within 30s online in a hurry). In the end, there were 100 valid copies left.

Among these valid copies, 41 copies were completed by respondents under age 25, accounting for $41 \%$; 38 copies at age 25-30, accounting for 38\%; 21 copies above age 30, accounting for $21 \%$. Moreover, 32 copies were filled by respondents below college degree, accounting for 32\%; 48 copies with college degree, accounting for 48\%; 20 copies with master degree, accounting for $20 \%$. Among them, 31 respondents had no work experience, accounting for 31\%; 46 had work experience between 0 -3 years, accounting for 46\%; 23 had work experience above 3 years, accounting for $23 \%$. With regard to whether any family member started a business before, 45 respondents had, accounting for $45 \%$; and 55 respondents did not have, accounting for 55\%.

\section{Empirical Analysis}

Reliability Analysis. Before data analysis, it is necessary to take into account the reliability of sample, so as to ensure the quality of measurement. The reliability of questionnaire is employed to find out the reliability of questionnaire measurement. This paper takes three dimensions for reliability analysis, i.e. proactive personality, entrepreneurial attitude and entrepreneurial intention within five years. Hence, the following table presents the results: 
Table 1 Reliability analysis

\begin{tabular}{|l|c|c|}
\hline & Cronbach's Alpha & Entries \\
\hline Proactive personality & .969 & 18 \\
\hline Entrepreneurial attitude & .919 & 7 \\
\hline Entrepreneurial intention within five years & .911 & 4 \\
\hline
\end{tabular}

As revealed in Table 1, the Alpha value of proactive personality is 0.969 , which is larger than 0.9 , so the dimension of proactive personality is reliable. The Alpha value of entrepreneurial attitude is 0.919 , which is also larger than 0.9 , so the dimension of entrepreneurial attitude is reliable. The Alpha value of entrepreneurial intention within five years is 0.911, which is larger than 0.9 , so the dimension of entrepreneurial intention within five years is reliable as well. Based on the data in the above table, the questionnaire used in this paper has very good reliability.

Relevance Analysis. This study performs the relevance analysis on three dimensions, i.e. proactive personality, entrepreneurial attitude and entrepreneurial intention within five years, so as to obtain the results as presented in Table 2:

Table 2 Relevance analysis

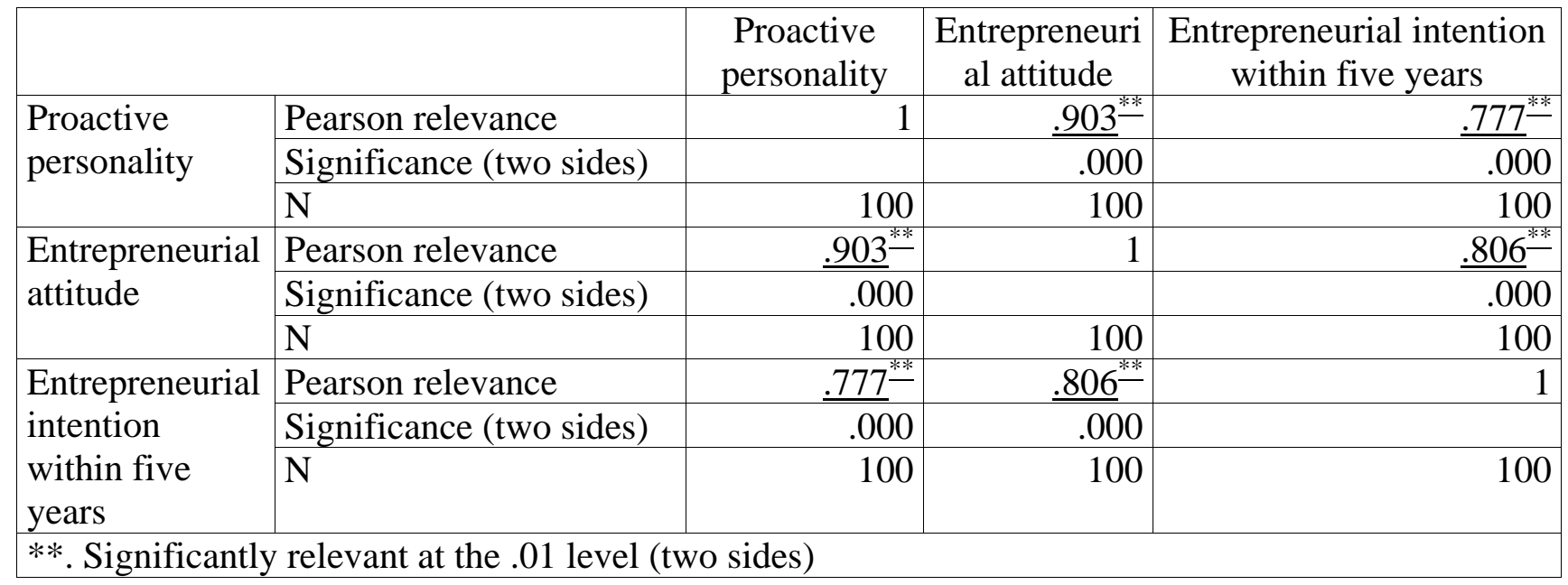

As revealed in the above table, the relevance coefficient of proactive personality with entrepreneurial attitude and entrepreneurial intention within five years is 0.903 and 0.777 respectively, so proactive personality is significantly relevant to entrepreneurial attitude and entrepreneurial intention within five years. The relevance coefficient of entrepreneurial attitude with proactive personality and entrepreneurial intention within five years is 0.903 and 0.806 respectively, so entrepreneurial attitude is significantly relevant to proactive personality and entrepreneurial intention within five years. The relevance coefficient of entrepreneurial intention within five years with proactive personality and entrepreneurial attitude is 0.777 and 0.806 respectively, so entrepreneurial intention within five years is significantly relevant to proactive personality and entrepreneurial attitude. Hence, the above hypotheses 1 and 2 have been verified.

Regression Analysis. This study employs the collected data for regression analysis to explore the relationships among proactive personality, entrepreneurial attitude and entrepreneurial intention within five years as presented in the following table: 
Table 3 Regression Analysis on Proactive Personality

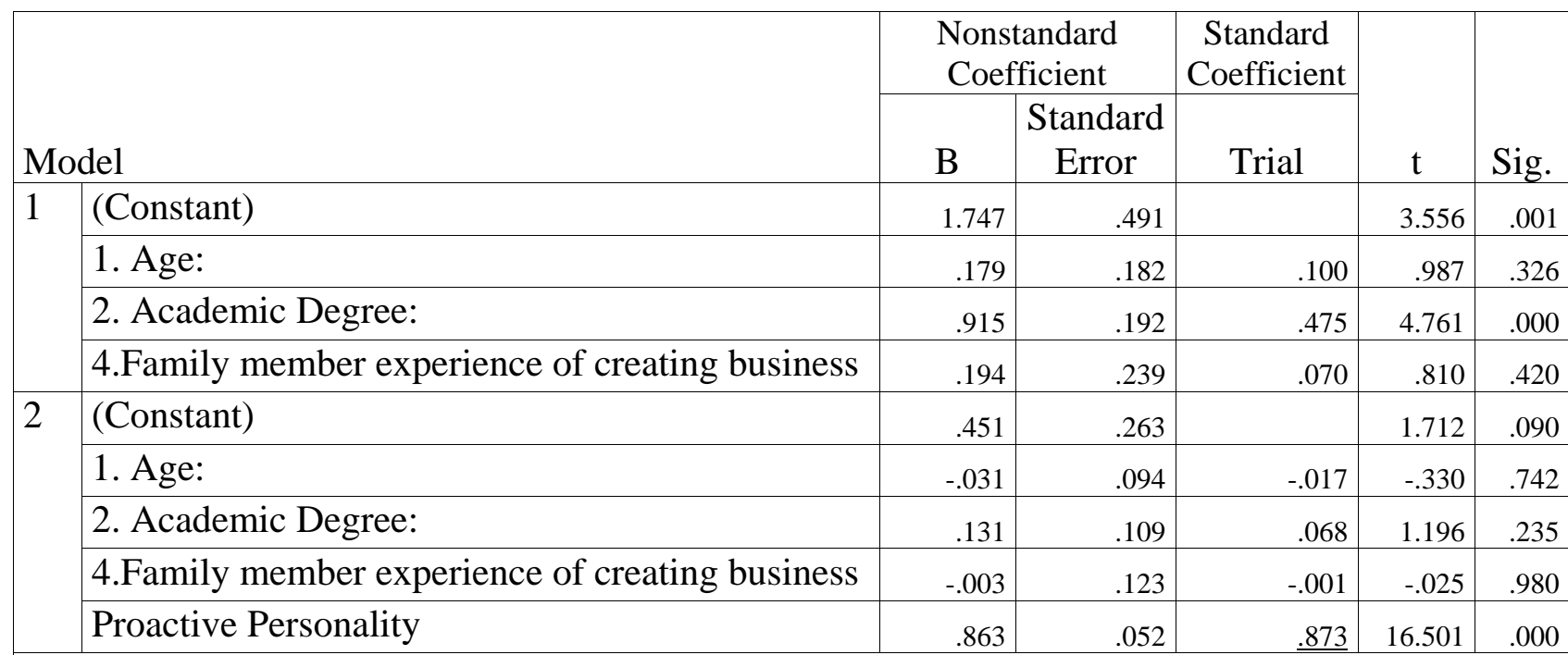

a. Dependent variable: Entrepreneurial attitude

Based on the relevance analysis, it is concluded that proactive personality is significantly relevant to entrepreneurial intention. It is assumed that the proactive personality is $\mathrm{X}$, entrepreneurial attitude is $\mathrm{Y}$, entrepreneurial intention is $\mathrm{Z}$. As entrepreneurial attitude is a dependent variable and $\mathrm{Z}=0.873 \mathrm{X}$, the standardized regression formula is $\mathrm{Z}=0.873 \mathrm{X}$.

Table 4 Regression Analysis of Survey Respondents

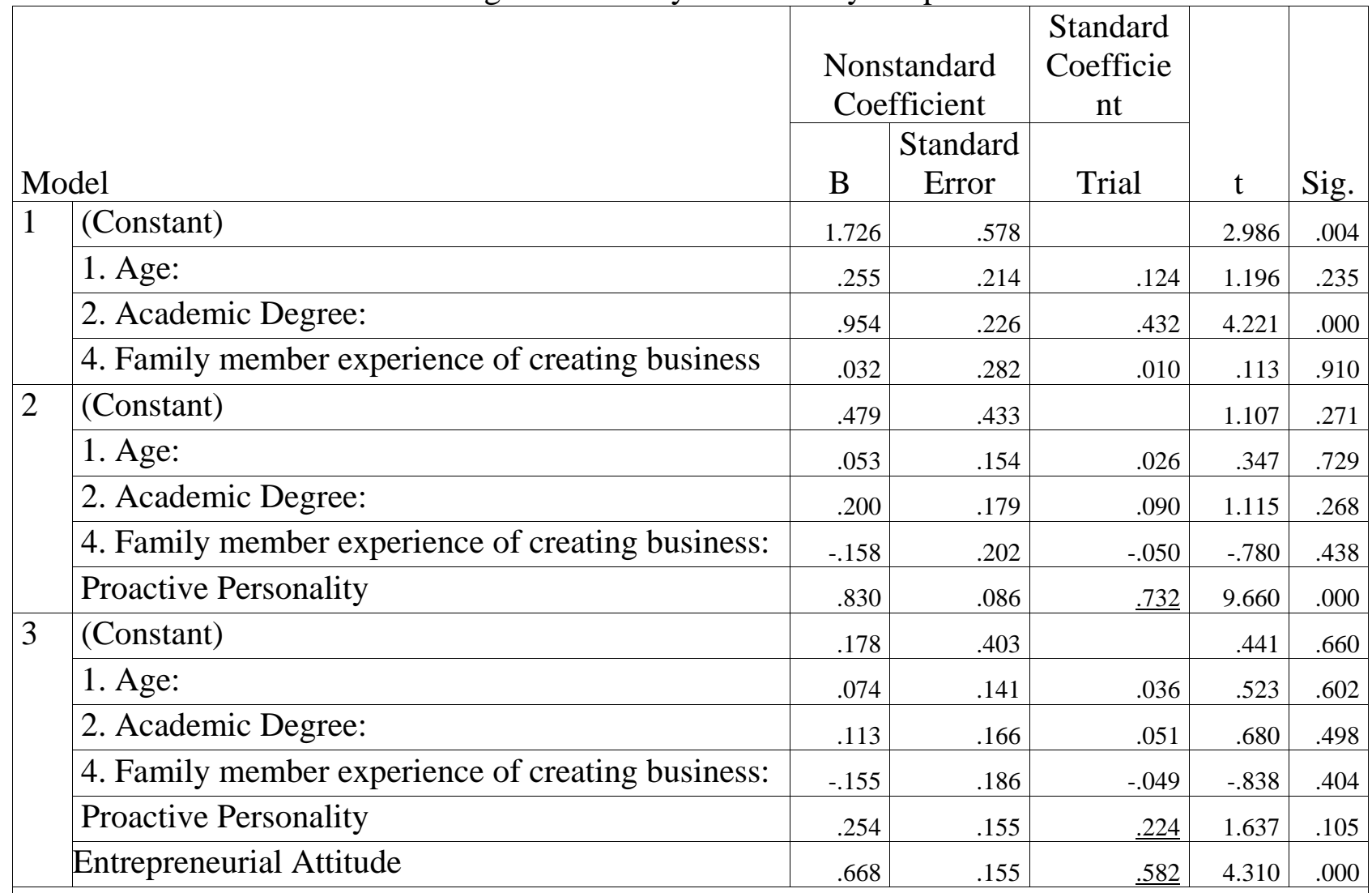

a. Dependent variable: Entrepreneurial intention within five years

Based on the relevance analysis, it is concluded that proactive personality is significantly relevant to entrepreneurial attitude. Taking the age and academic degree of survey respondent and whether any family member started a business before as the constants and the entrepreneurial intention within five years as a dependent variable, if $\mathrm{Y}=\mathrm{a} 2+\mathrm{b} 2 \mathrm{X}$, the standardized regression formula is $\mathrm{Y}=0.732 \mathrm{X}$.

Based on the relevance analysis, it is concluded that entrepreneurial attitude is significantly relevant to entrepreneurial intention. Taking the age and academic degree of survey respondent and 
whether any family member started a business before as the constants, the entrepreneurial intention within five years as a dependent variable, and the entrepreneurial attitude as a mediator variable, if $\mathrm{Y}=\mathrm{a} 3+\mathrm{b} 3 \mathrm{X}+\mathrm{c} 1 \mathrm{Y}$, the standardized regression formula is $\mathrm{Z}=0.224 \mathrm{X}+0.582 \mathrm{Y}$.

Based on the above analysis, we find that, when entrepreneurial attitude is a mediator variable, the coefficient of proactive personality is decreasing, indicating that proactive personality affects entrepreneurial attitude directly and entrepreneurial attitude determines entrepreneurial intention directly. Entrepreneurial attitude plays a role in mediating the influence of proactive personality on entrepreneurial intention. Hence, the hypothesis 3 is verified.

\section{Conclusion and Prospects}

This study surveys the proactive personality and entrepreneurial intention of full time mothers, and reveals the positive correlation between entrepreneurial attitude and entrepreneurial intention, the positive correlation between proactive personality and entrepreneurial intention, and the entrepreneurial attitude as a mediator between proactive personality and entrepreneurial intention. Hence, not all full time mothers are suitable or able to start a business, so whether a full time mother starts a business depends on the existence of proactive personality and her attitude towards entrepreneurship. Full time mothers should not follow the trend blindly, in order to prevent more losses. In addition, this study will also provide the reference for the personal career development of full time mothers.

\section{References}

[1] F. Wen, J.P. Mao, Proactive personality theory overview, Science of Social Psychology 120 (2011), 15-19.

[2] Crant J M, Bateman T S. Charismatic lead-ership viewed from above: The impact of proactive personality. Journal of Organizational Behavior, 2000,21: 63-75

[3] Becherer R C, Maurer J G. The proactivepersonality disposition and entrepreneurial behavior among small company presidents. Journal of Small Business Management, 1999, 38(1): 28- 36

[4] Z. Liu, X.K. Zhang, Y.L. Zou, The latest progress of study on entrepreneurial intention of college students in China, Journal of Northeast Normal University (Philosophy and Social Sciences), 6 (2012), 233-236. 